\title{
UHF RFID Reader Antenna using Novel Planar Metamaterial Structure for RFID System
}

\author{
Marwa Zamali, Lotfi Osman, Hedi Ragad \\ UR "CSEHF" 13ES37, FST, \\ University of Tunis El Manar \\ 2092 Tunis, Tunisia
}

\author{
Mohamed Latrach \\ ESEO Institute of Science \& Technology \\ 49107 Angers, \\ France
}

\begin{abstract}
An Ultra High Frequency (UHF) half-loop antenna used in Radio Frequency Identification (RFID) systems is proposed with a planar patterned metamaterial structure of compact size. The size of the planar patterned metamaterial structure is $(0.20 \lambda * 0.20 \lambda * 0.0023 \lambda) \mathrm{mm}^{3}$. This antenna consists of two metamaterial unit cells having negative permittivity and permeability. Simulation results of input return loss, radiation pattern, and directivity of this antenna are presented using CST software. A comparison between the conventional antenna and the new metamaterial half-loop antenna is also provided. The simulated results show that the metamaterial antenna has a resonance frequency of $0.866 \mathrm{GHz}$, a realized gain of $1.96 \mathrm{~dB}$, and an efficiency increase of about $20 \%$. Simulation and measurement results are in perfect agreement, which proves that the proposed antenna can operate in the UHF band for RFID systems.
\end{abstract}

Keywords-Loop antenna; metamaterial; miniaturization; RFID system; UHF band

\section{INTRODUCTION}

Nowadays, antennas play a very important role in tracking any object using the automatic identification technology. This technique has been increased in many fields like industry, business, food and library management, and so on [1]. In wireless communications, the RFID systems are one of the most promising technologies [2] that emerged after automatic identification to detect any object anywhere [3], [4]. They are now widespread in many industrial applications such as merchant flow tracking, stock, control, and supply chain management [5], [6].

The UHF RFID systems are used in different regions of the world. We will be interested in the European UHF band which is between $865 \mathrm{MHz}$ and $868 \mathrm{MHz}$ [7], [8]. The drawback of this band is the need of a large antenna, which led researchers to look for a solution minimizing the size of the antenna while keeping its performance. There are several methods of reducing the size of the antenna such as the use of short circuits (PIFA), slot antennas, and fractal shapes [9][12]. However, these techniques do not allow having a good performance in terms of impedance, directivity, and large wide band, hence the interest in the use of metamaterials [13], [14] to decrease the resonance frequency and maintain the performance of the antenna. Metamaterials, which were propounded by Victor Veselago in 1968, are also called lefthanded materials (LHM) because the vectors $\mathrm{E}, \mathrm{H}$, and $\mathrm{K}$ form a left-handed system [15], [16].
This work treats a half-loop antenna coupled with a novel structure of metamaterial to decrease the resonance frequency by $20 \%$ and increase the gain by $76 \%$. The obtained results are shown by a numerical software using CST-MWS and validated by experimental results. The presented paper falls into three parts. In the first section, the physical and design for the structure of metamaterial are presented and simulated regarding the S11 and S12 to find the permeability and permittivity. The second section shows the simulation results for the proposed antenna presenting the return loss and the realized gain, that's why in the thirst section; the antenna is coupled with metamaterial to achieve the desired results in terms of the resonance frequency, realized gain and radiation pattern. In the last section, the metamaterial is validated by the experimental result.

\section{Presentation of the New Metamaterial STRUCTURE}

The concept of artificial material, i.e. metamaterial, was synthesized in the late 90s. However, in the past 20 years, the interest in metamaterial technology has strongly increased with researchers on superlens and telecommunication environments, including transmission lines and antenna applications. Metamaterials are artificial materials obtained by regulating the interactions of materials with electromagnetic (EM) waves to make them acquire specific properties [17]. The photonic metamaterial patterns to be incorporated on the antenna were made through 4-level fractal structures, which are sometimes called a space filling curves. The fractal pattern is generated by a master line or the first level of the structure. The multi-band functionality and sub-wavelength effect are the two most important features of this $\mathrm{S}$ and $\mathrm{U}$-shaped fractal. The main advantages of the fractal cell are its sub-wavelength properties, simple architecture, and wide application. The subwavelength allows the system to have a smaller size when compared with the wavelength. Thus, the cell can behave as a compact reflector. In the case of metamaterials, the curl of electric field $\mathrm{E}$ and magnetic field $\mathrm{H}$ have a power density $\mathrm{S}=\mathrm{E} \times \mathrm{H}$ and moves in the opposite direction of the wave vector $k$. The most important two parameters of electromagnetic waves are Electric Permittivity $\mathcal{E}$ and magnetic permeability $\mu$. Fig. 1 shows the geometry of the fractal unitary metamaterial cell. In order to calculate the effective values of permittivity and permeability, the Nicolson-Ross-Weir (NRW) approach is used [18]. The equations are as follows: 


$$
\begin{gathered}
\mathrm{n}=\frac{1}{K d} \cos ^{-1}\left[\frac{1}{2 S_{21}}\left(1-S_{11}^{2}+S_{21}^{2}\right)\right] \\
Z=\sqrt{\frac{\left(\left(1+\mathrm{S}_{11}\right)\right)^{2}-\mathrm{S}_{21}^{2}}{\left(1-\mathrm{S}_{11}\right)^{2}}}
\end{gathered}
$$

Where, the $\mathrm{S}$ parameters result from CST simulation, $\mathrm{n}$ and $\mathrm{z}$ are related to the relative permittivity and permeability.

$$
\varepsilon=\frac{n}{Z}, \mu=\frac{n}{Z}
$$

Table 1 below presents the dimensions of the proposed metamaterial cell.

Fig. 2 shows the S-parameters of the new metamaterial structure whose band gap ranges from 0.855 to $1.12 \mathrm{GHz}$.

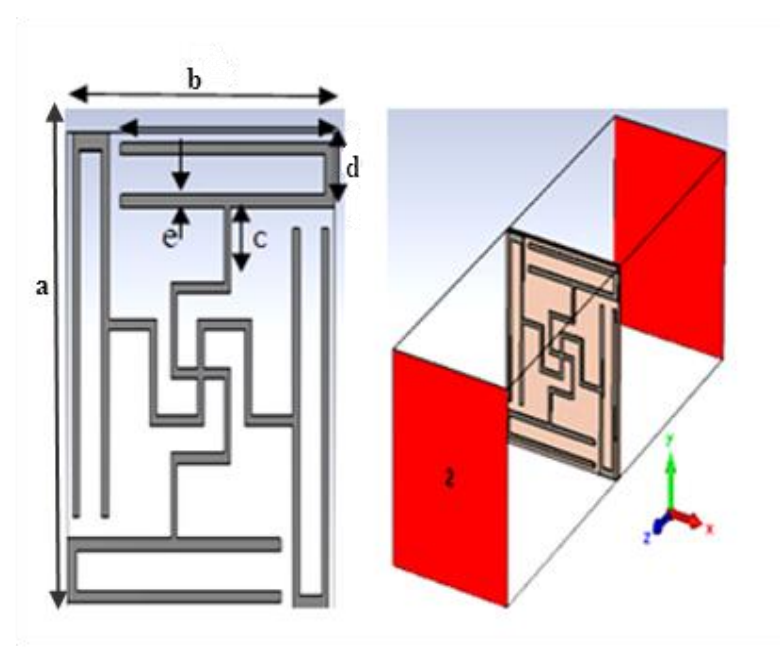

Fig. 1. Geometry of the proposed metamaterial cell.

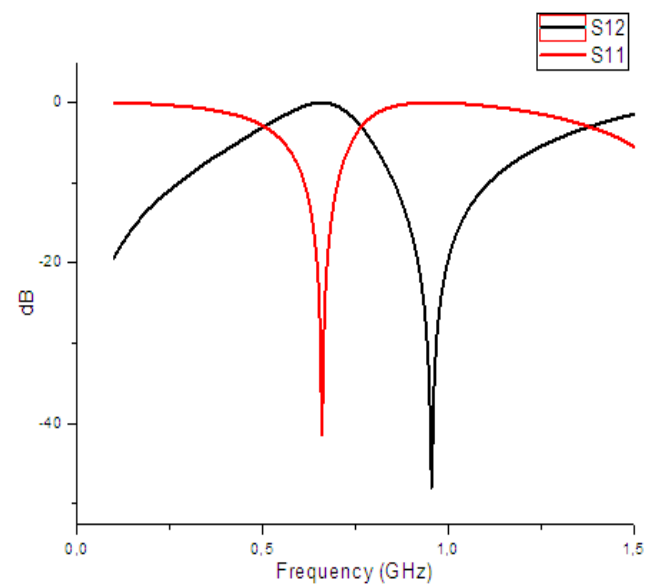

Fig. 2. Parameters of the novel metamaterial structure.

TABLE I. Dimensions of THE Proposed Metamaterial CELL

\begin{tabular}{|l|l|l|l|l|}
\hline $\mathbf{a}(\mathrm{mm})$ & $\mathbf{b}(\mathrm{mm})$ & $\mathbf{c}(\mathrm{mm})$ & $\mathbf{d}(\mathrm{mm})$ & $\mathbf{e}(\mathrm{mm})$ \\
\hline 28 & 22 & 5 & 3.75 & 0.5 \\
\hline
\end{tabular}

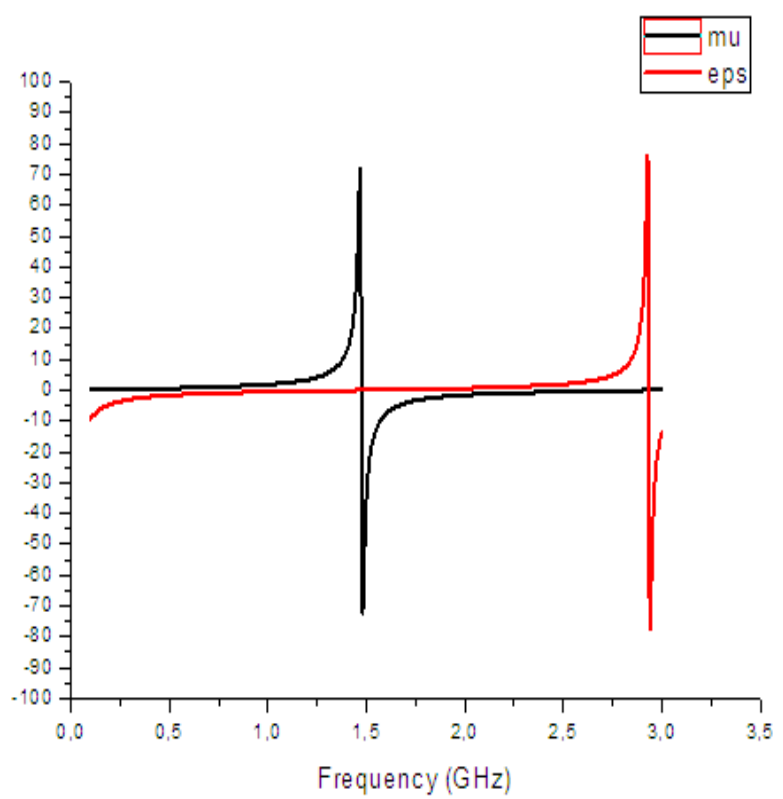

Fig. 3. Real part of the relative permittivity and the permeability.

Fig. 3 presents the real part of the relative permittivity and the permeability. It may be noted that the real part of the permittivity is negative around the resonance frequency.

\section{DESIGN OF THE HALF-LOOP ANTENNA}

A half-loop antenna is a closed circuit antenna that consists of a single wire bent into a half circle and mounted on a ground plane. The conductor is fed through the ground plane at one end while the other end is terminated on the ground plane. The half-loop antenna exists in various forms, but in this paper, the circular form will be used. The small size and high efficiency are the advantages of a properly designed halfloop antenna constructed on the UHF frequency band.

\section{A. Half Loop Antenna Without Metamaterial}

Fig. 4 exhibits the basic structure of the half-loop antenna without metamaterial cells. It consists of a circular half-loop of $30 \mathrm{~mm}$ radius $\mathrm{R}$ resonating at $1.05 \mathrm{GHz}$ printed on an FR4 substrate $\left(\varepsilon_{\mathrm{r}}=4.4, \mathrm{~h}=0.8 \mathrm{~mm}\right.$ and $\left.\tan \delta=0.0008\right)$. The simulated frequency and the realized gain are shown in Fig. 5 and 6, respectively.

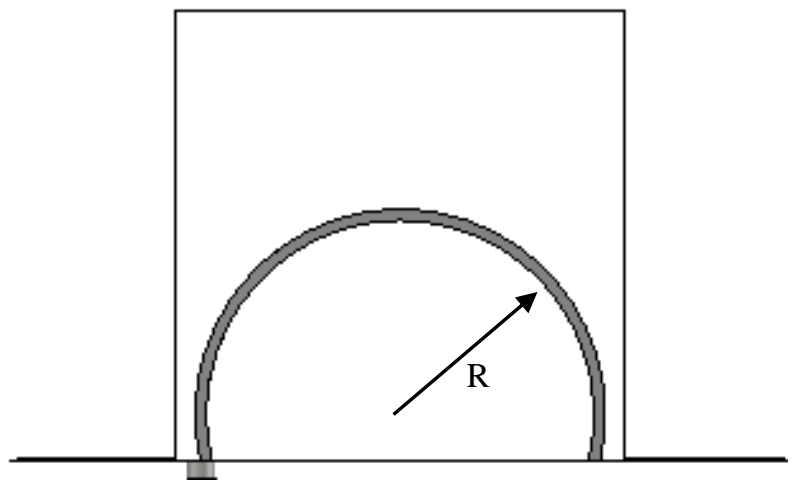

Fig. 4. Design of the proposed antenna. 


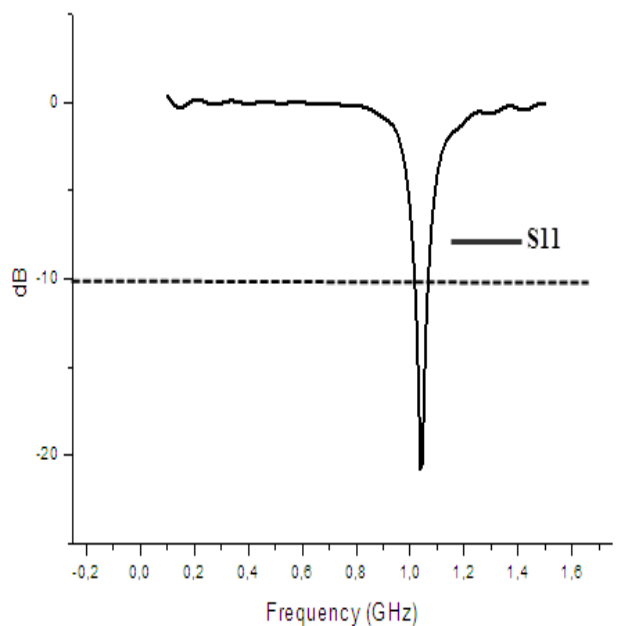

Fig. 5. Reflection coefficient of the antenna without metamaterial.

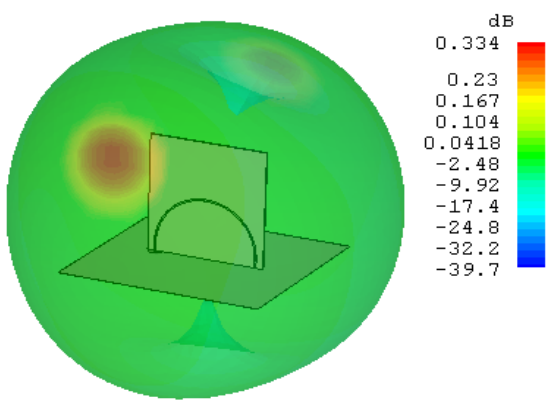

Fig. 6. Realized gain at $0.866 \mathrm{GHz}$ of the antenna without metamaterial.

One important property of antenna is the efficiency. It can be written as the ratio of the total radiated power $\mathrm{P}_{\mathrm{r}}$ to the input power $\mathrm{P}_{\mathrm{i}}$ of the antenna.

$$
\mathrm{\eta}=\frac{P_{r}}{P_{i}}=\frac{\text { Gain }}{\text { Directivity }} \times 100
$$

The realized gain of the antenna without metamaterial is $0.33 \mathrm{~dB}$, likewise, the directivity is about $2.11 \mathrm{dBi}$. So, the efficiency of the antenna without metamaterial is $68 \%$.

\section{B. Half Loop Antenna with Metamaterial}

An important fraction of the radiation gets lost in the substrate above the radiant element and on the edges around the structure. This problem is occurred by surface waves and leakage waves which limit the performance of the antenna. To overcome this limitation, we use metamaterial cells to prevent the distribution of the surface waves. The addition of the metamaterial cells serves to reduce the resonance frequency, hence miniaturizing the structure. Adding metamaterial cells in the half-loop antenna modifies the radiation pattern by focusing the energy in one direction [19], [20] and it is completely confined under the radiating element.

The proposed antenna shown in Fig. 7 has a loop radius (r) of $30 \mathrm{~mm}$ and a width $(\mathrm{w})$ of $1.25 \mathrm{~mm}$. This half-loop is integrated on an FR4 substrate of $70 \mathrm{~mm} * 70 \mathrm{~mm} * 0.8 \mathrm{~mm}$ (the same substrate of the metamaterial cells) that is perpendicular to a ground plane of $120 \mathrm{~mm} * 120 \mathrm{~mm} * 0.1 \mathrm{~mm}$, and is simulated through the use of the CST software.

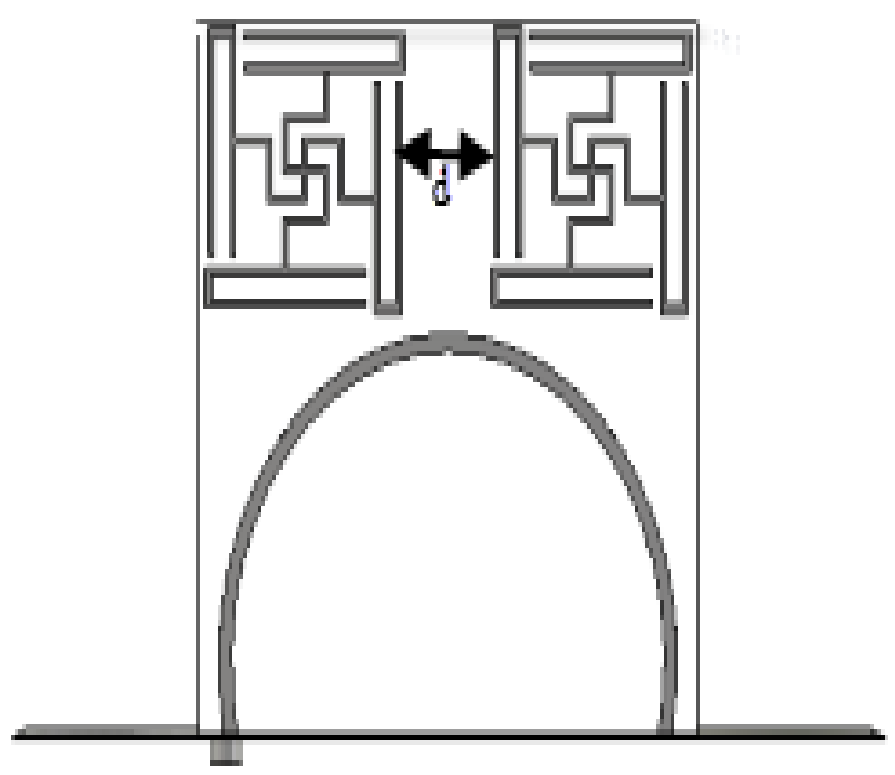

Fig. 7. Design of the metamaterial antenna.

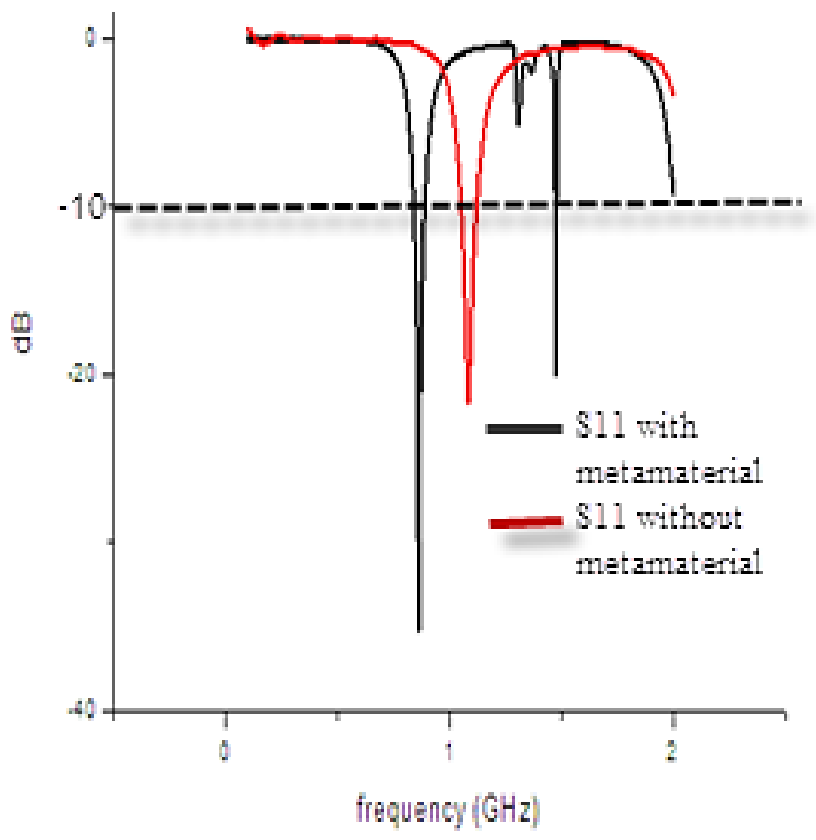

Fig. 8. Reflection coefficient of the antenna with and without metamaterial.

The proposed half-loop antenna with metamaterial cells exhibited better results in terms of return loss, with $-36 \mathrm{~dB}$ against $-22 \mathrm{~dB}$, and diminution of resonance frequency from $1.05 \mathrm{GHz}$ to $0.866 \mathrm{GHz}$. The $\mathrm{S} 11$ parameters for the two designs are shown in Fig. 8.

This figure shows that the use of metamaterials cells allows the decrease of the resonance frequency from $1.05 \mathrm{GHz}$ to $0.866 \mathrm{GHz}$, i.e. a decrease of about $185 \mathrm{MHz}$. To understand the performance of distance between the two metamaterial cells, we examined the effects on return loss when varying parameter $\mathrm{d}$. The simulation of the resonance frequencies for different values of $d$ is presented in Fig. 9. 


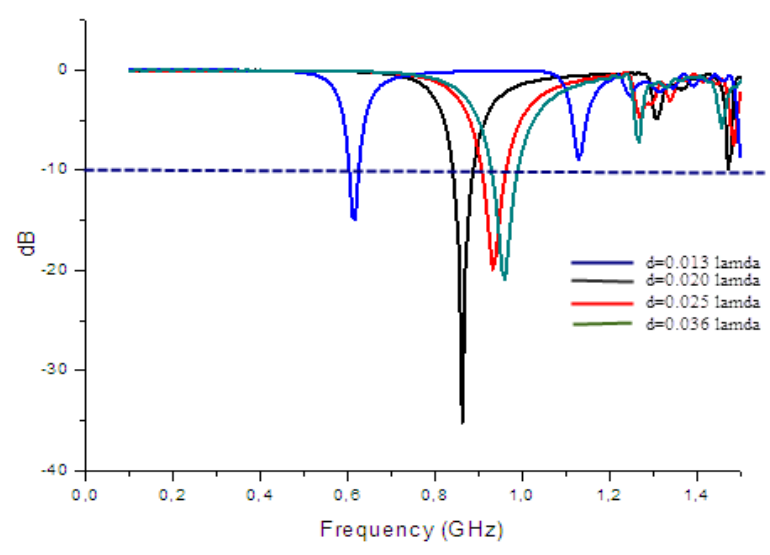

Fig. 9. Effects of the distance $d$ on the return loss.

Fig. 9 shows the effects of distance $d$ on the resonance frequency, we can notice that the resonance frequency is decreased when the distance between both cells is decreased. However, the gain at the low resonance frequency $\left(f_{r}=0.61\right.$ $\left.\mathrm{GHz}, \mathrm{d}=0.036 \lambda_{0}\right)$ is negative, on which the antenna has been chosen whose distance separating the two cells is approximately $8 \mathrm{~mm}\left(\mathrm{~d}=0.020 \lambda_{0}\right)$. The novel antenna exhibits better results in terms of gain, with a simulated gain of about $1.93 \mathrm{~dB}$ with against $0.44 \mathrm{~dB}$ without metamaterials.

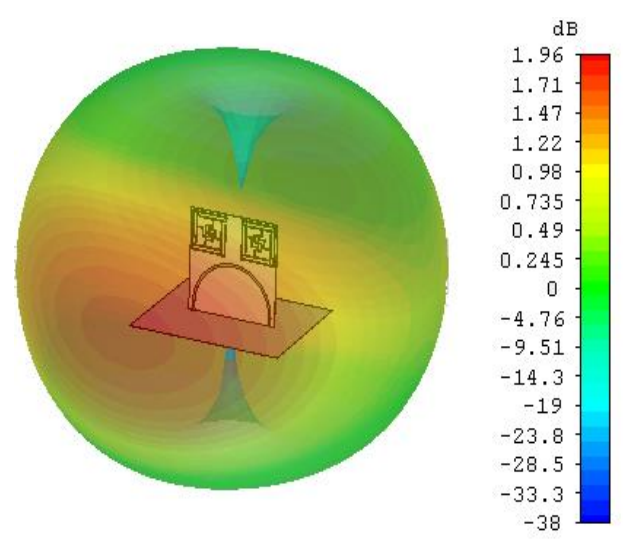

Fig. 10. Realized gain at $0.866 \mathrm{GHz}$ of the metamaterial antenna.

Fig. 10 shows that the realized gain at $866 \mathrm{MHz}$ of the metamaterial antenna is about $1.93 \mathrm{~dB}$. The simulated directivity of metamaterial antenna is $2.11 \mathrm{dBi}$. Theoretically [21], the maximum gain of aperture antenna is expressed as:

$$
\mathrm{D}_{\max }=\frac{4 \pi A}{\lambda_{0}^{2}}
$$

Where, $\left\{\begin{array}{c}A=L^{2} * m \\ \lambda_{0}=\frac{C_{0}}{f_{0}}\end{array}\right.$

$\mathrm{L}$ is the length of the ground plane, $\mathrm{m}$ is the length of the substrate and $\mathrm{A}$ is the aperture of the antenna. So $\mathrm{D}_{\max }=2.73$ $\mathrm{dBi}$. The simulated directivity of metamaterial antenna has almost approached the theoretically limit of the antenna's directivity with percentage error $(5 \%)$.

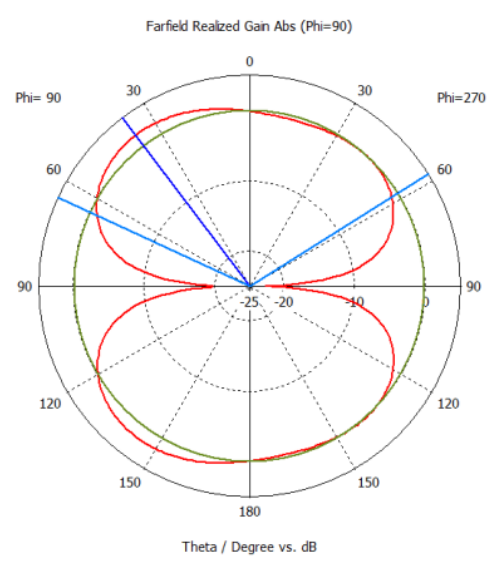

Fig. 11. Simulated radiation pattern in the E-plane at $0.866 \mathrm{GHz}$.

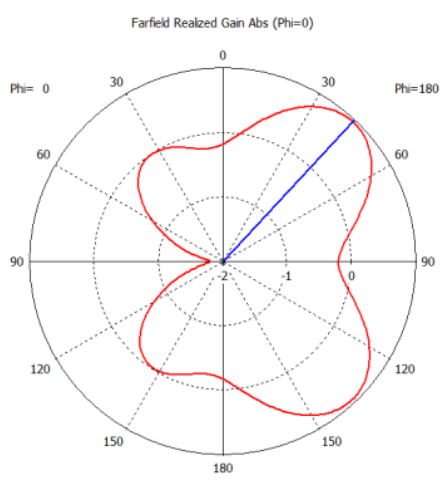

Fig. 12. Simulated radiation pattern in the H-plane at $0.866 \mathrm{GHz}$.

Fig. 11 and 12 show the simulated radiation pattern in plane $\mathrm{E}$ and $\mathrm{H}$, respectively. We can notice that the simulated $3 \mathrm{~dB}$ beam width for this antenna with metamaterial is decreased by $57^{\circ}$ at plane $\mathrm{E}$ which implies an increase in directivity. The efficiency of the antenna with metamaterial is about $87 \%$, that's why it may be concluded that thanks to the metamaterials that efficiency has improved.

Table 2 summarizes the characteristic values of the antenna with and without metamaterial in terms of resonance frequency, frequencies range, and bandwidth which are calculated by the following equation:

$$
\mathrm{BW} \%=\frac{2\left(\mathrm{f}_{\max }-\mathrm{f}_{\min }\right)}{\left(\mathrm{f}_{\max }+\mathrm{f}_{\min }\right)} \times 100
$$

TABLE II. CHARACTERISTICS OF THE ANTENNA WITHOUT AND WITH METAMATERIAL

\begin{tabular}{|l|l|l|}
\hline & $\begin{array}{l}\text { Without } \\
\text { metamaterial }\end{array}$ & $\begin{array}{l}\text { With } \\
\text { metamaterial }\end{array}$ \\
\hline & & \\
\hline$f_{r}(\mathrm{GHz})$ & 1.04 & 0.866 \\
\hline $\mathrm{RL}(\mathrm{dB})$ & 21 & 36 \\
\hline$f_{\min }(\mathrm{GHz})$ & 1 & 0.863 \\
\hline$f_{\max }(\mathrm{GHz})$ & 1.1 & 0.869 \\
\hline $\mathrm{BW}(\%)$ & 4.7 & 0.34 \\
\hline Gain $(\mathrm{dB})$ & 0.33 & 1.96 \\
\hline Directivity(dB) & 2.11 & 2.59 \\
\hline Efficiency $(\%)$ & 68 & 87 \\
\hline
\end{tabular}




\section{SimUlation AND EXPERIMENTAL RESUlTS}

The novel antenna with and without metamaterial cells are realized in the Maxwell Laboratory of group ESEO-Angers, France. Fig. 13 illustrates the experimental prototypes whose ground planes have the dimensions of $12 \mathrm{~cm} \times 12 \mathrm{~cm}$.

Simulated and measured S11 parameter of the antenna with and without metamaterial cells are presented in Fig. 14.

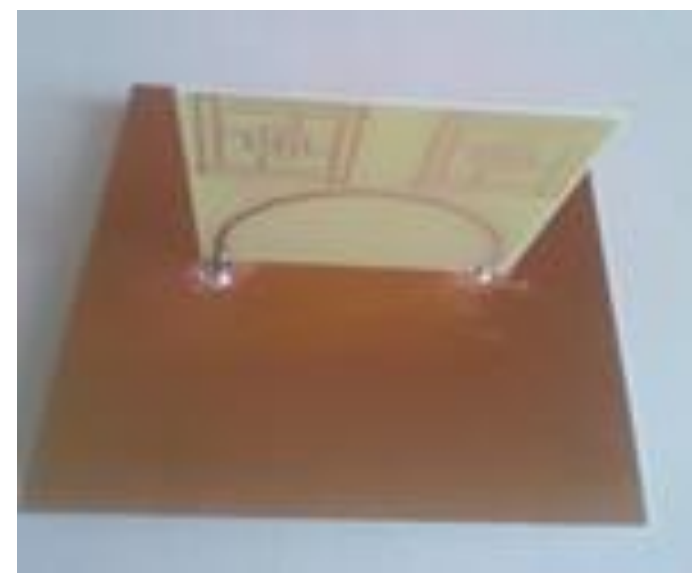

Fig. 13. Realized metamaterial antenna.

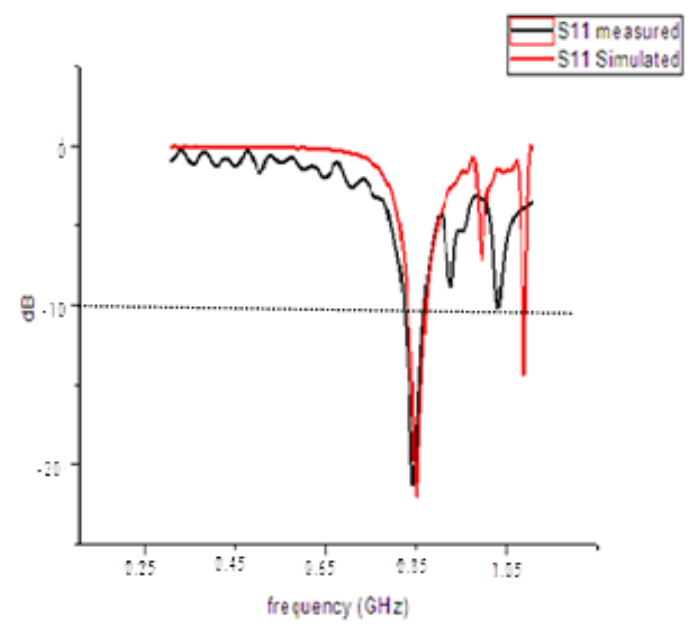

Fig. 14. Simulated and measured $|\mathrm{S} 11|$ of the metamaterial antenna.

\section{CONCLUSION}

In this paper, a novel metamaterial cell is designed with negative permittivity and permeability. When metamaterial cells are applied to the antenna, this leads to an improvement in the gain and the radiation patterns with a decrease in the resonant frequency. Measurements on the manufactured prototype validated the simulation results carried out under CST software. As perspective to the study, the proposed antenna could be used in libraries for identification, sorting and transportation of library books.

\section{ACKNOWLEDGMENT}

The authors would like to thank the ESEO (Ecole Supérieure d'Electronique de l'Ouest) of Angers-France for their support and assistance during the preparation of this research paper.

\section{REFERENCES}

[1] Priyanka Grover, Anshul Ahuja, "Radio Frequency Identification based library management system," International Journal of Advanced Computer Science and Applications, Vol. 1, No. 1, July 2010.

[2] K. Finkenzeller, "Fundamentals and Applications in Contactless Smart Cards and Identification," RFID Handbook, New York: Wiley, 2003.

[3] Daniel W. Engels, Tom A. Scharfeld, Sanjay E. Sarma," Review of RFID Technologies," Cambridge, MA USA 02139.

[4] Arttu Lehto, Jussi Nummela, Leena Ukkonen, Lauri Sydanheimoand Markku Kivikoski, "Passive UHF RFID in Paper Industry: Challenges, Benefits, and the Application Environment," IEEE Transactions on Automation Science and Eng., vol. 6, no. I, pp. 66-79, Jan. 2009.

[5] K. Finkenzeller, "Radio-frequency identification fundamentals and applications," RFID Handbook: 2nd edition, Wiley, West Sussex, England, 2004.

[6] J. Sabri, N.omrane, T. Hichem, M. Abdelkader, G. Ali, "Miniaturized meander slot for RFID tag with dielectric resonator at $60 \mathrm{GHz}$," International Journal of Advanced Computer Science and Applications, vol. 7 , no. 4, 2016

[7] K. Finkenzeller, RFID Handbook: Radio-Frequency Identification Fundamentals and Applications. New York: Wiley, 2002.

[8] V. D. Hunt, A. Puglia, and M. Puglia, "RFID-A Guide to Radio Frequency Identification” Hoboken, NJ: Wiley, 2007.

[9] S. Pflaum, G. Kossiavas and R. Staraj, "Circularly polarized wire patch antenna for RFID applications," 6th European Conference on Antennas and Propagation (EUCAP), pp. 2997-3000, 2012.

[10] K. L. Wong, and C.C. Huang, and W.S. Chen, "Printed Ring slot antenna for circular Polarization Propagation," AP-50, 1, pp.75-77, January 2002.

[11] Marwa Zamali, Lotfi Osman, Hedi Ragad and Mohamed Latrach, "A Novel Miniaturized Circularly Polarized PIFA Antenna for RFID Readers," IEEE 15th Mediterranean Microwave Symposium (MMS), Lecce, Italy, Nov. 30 2015-Dec. 22015.

[12] J.Y. Sze, and C.C. Huang, "Coplanar wave guide- Fed square slot antenna for Broad band circular Polarization Radiation," IEEE transac. on antennas and propagation, vol. 51, no. 8, pp.2141-2144, Aug. 2003.

[13] Zeev Iluz, Reuven Shavit, and Reuven Bauer, "Microstrip Antenna Phased Array with Electromagnetic Band gap Substrate," IEEE Trans. on Antennas and Propag., vol. 52, No. 6, pp. 1446-1453, June 2004.

[14] Fan Yang and Yahiya Rahmat-Samii, "Microstrip Antennas Integrated With Electromagnetic Band-Gap (EBG) Structures: A Low Mutual Coupling Design for Array Applications," IEEE Transactions on Antennas and Propagation. vol. 51, no.10, pp.2936-2946, Oct. 2003.

[15] B.zarghooni, A. Dadgarpour, and T. A. Denidi, "Reconfigurable planar metamaterial unit cell," Phil. IET Microwaves Antenna \& propagation, vol. 9, no. 10, pp. 1074-1079, March 2015.

[16] Ludovic Leger,Thierry Monediere and Bernard Jecko, "Enhancement of gain and radiation bandwidth for a planar 1-D EBG Antenna," IEEE Antennas Wireless Comp. Lett., vol.15, no.9, pp.573-575, Sept. 2005.

[17] S. A. Ramakrishna, "Physics of negative refractive index materials," Rep. Prog. Phys., 2005, 68, 449-521.

[18] Richard R. Ziolkowski, "Double Negative Metamaterial Design, Experiments and Application," IEEE on Microwave Theory and Techniques, vol. antenna's miniaturization and high directivity. 51, No. 7, July 2003.

[19] S.-Y. Chen, R.O. Ouedraogo, A. Temme, A.R. Diaz, E.J. Rothwell, "MNG- Metamaterial- Based Efficient Small Loop Antenna," IEEE APSURSI 2009, pp. 1-4.

[20] E. Ramanandraibe, M. Latrach, and A. Sharaiha, "A half loop antenna associated with one SRR cell,” ICEAA 2013, Italy, September 2013.

[21] F. Zhu, Qingchun Lin and Jun Hu, "A Directive Patch Antenna with a Metamaterial Cover," Asia-Pacific Microw. Conf. Proc., vol. 1, 2005. 